\title{
ĐÁNH GIÁ KẾT QUẢ PHẪU THUẠTT TRIỆT ĐỂ TƯ CHÚNG FALLOT TẠI BỆNH VIỆN TIM HÀ NỘI GIAI ĐOẠN 2011-2015
}

Nguyễn Sinh Hiền*

\section{TÓM TÁT:}

155 bệnh nhân, tuổi trung bình $9,88(0,41$ 54 t); tỷ lệ miếng vá xuyên vòng van $38,7 \%$; chênh áp thất phải - động mạch phổi sau mổ $18,87 \pm 11,60 \mathrm{mmHg}$; tỷ lệ áp lực tối đa thất phải/thất trái $0,57 \pm 0,16$. Biến chứng sau mổ 20,6\%. Tỷ lệ mổ lại sớm 2,56\%.Tỷ lệ tử vong tại viện $1,29 \%$. Sau mổ 6 tháng (153 bệnh nhân): tỷ lệ mổ lại $0 \%$, tử vong $0 \%$. Sau mổ 3 năm $(60$ bệnh nhân): mổ lại $0,65 \%$, tử vong $0 \%$; không có sự thay đổi về: chỉ số giãn thất phải, chênh áp thất phải- động mạch phổi, thời gian QRS. Kết quả phẫu thuật triệt để tứ chứng Fallot theo phương pháp không mở thất phải tại Bệnh viện Tim Hà Nội là khả quan với tỷ lệ tử vong thấp.

Từ khóa: Tứ chứng Fallot, sửa triệt để, bệnh tim bẩm sinh.

\section{SUMMARY:}

155 patients had surgery at a mean age of 9,88 years $(0,41-54) . \quad 38,7 \%$ patients had transanullar patch. Mean RV-PA gradient postoperation was $18,87 \pm 11,6 \mathrm{mmHg}$. Maximum $\mathrm{RV} / \mathrm{LV}$ pressure $0,57 \pm 0,16.20,6 \%$ patients had complication, include $2,56 \%$ in need of reoperation. In-hospital mortality rate was $1,29 \%$. After 6 months $(\mathrm{n}=153)$ : reoperation $0 \%$, mortality $0 \%$. After 3 years $(n=60)$ : reoperation $0,65 \%$, mortality rate $0 \%$. There were no significant change in RV dilated index, RV-PA gradient, QRS time. The results of complete repair of TOF without ventriculotomy in Hanoi Heart Hospital were positive with low mortality rate. Keyword: Tetralogy of Fallot, complete repair, congenital heart disease.

\section{I. ĐặT VẤN ĐỂ}

Tứ chứng Fallot (TOF-Tetralogy of Fallot) là bệnh tim bầm sinh có tím, tần suất gặp $0,1 \%$ trẻ sinh ra còn sống. Bệnh gồm bốn tổn thương chính: hẹp động mạch phổi (ĐMP), thông liên thất (TLT), động mạch chủ (ĐMC) cưỡi ngựa trên vách liên thất, phì đại thất phải $(\mathrm{TP})$. Theo Kirklin, nếu không điều trị gì, $70 \%$ trẻ mắc TOF chết trước 10 tuổi, nếu được phẫu thuật triệt để, trẻ có thể sống như người bình thường [1]. Phẫu thuật triệt để gồm mở rộng đường ra TP và vá lỗ TLT. Các thao tác có thể thực hiện qua đường mở TP (phương pháp kinh điển) hoặc qua lỗ van ba lá và van ĐMP (không mở TP).Phương pháp không mở TP có những lợi ích vượt trội và được áp dụng cho tất cả các bệnh nhân TOF phẫu thuật triệt để tại Bệnh viện Tim Hà Nội. Mục đích của nghiên cứu là: đánh giá kết quả phẫu thuật triệt để TOF giai đoạn 2011-2015 tại bệnh viện Tim Hà Nội.

\section{II. ĐỐI TƯợNG VÀ PHƯỚNG PHÁP NGHIÊN CỨU}

\section{1.Đối tượng nghiên cứu:}

- Tiêu chuẩn lựa chọn: gồm các bệnh nhân TOF hẹp ĐMP được phẫu thuật triệt để tại bệnh viện Tim Hà Nội từ 1/2011 đến 1/2015. Hồ sơ đủ các dữ liệu .

- Tiêu chuẩn loại trừ: TOF không lỗ van động mạch phổi, TOF kèm tổn thương rất phức tạp khác: kênh nhĩ thất chung, Ebstein...

\subsection{Phương pháp nghiên cứu:}

- Phương pháp: mô tả, hồi cứu kết hợp

\footnotetext{
* Bệnh viện Tim Hà Nội

Ngườ chịu trách nhiệm khoa họ: TS. Nguyễn Sinh Hiền

Ngày nhận bài: 01/05/2018 - Ngày Cho Phép Đăng: 20/05/2018

Phản Biện Khoa học: PGS.TS. Đặng Ngocc Hùng
}

GS.TS. Lê Ngoc Thành 
tiến cứu

- Cõ̃ mẫu: xác định cỡ mẫu theo công thức:

$\mathrm{n} \geq \frac{Z^{2} \cdot \mathrm{p}(1-p)}{d^{2}}$

Trong đó: $\mathrm{n}=$ cỡ mẫu; $\mathrm{p}=$ tỷ lệ tử vong sớm sau mổ. Chúng tôi chọn $\mathrm{p}$ là $4 \%$. Z là mức có ý nghĩa thống kê, nếu lấy độ tin cậy là $95 \%$ thì $\mathrm{Z}=1,96$. $\mathrm{d}$ là sai số mong muốn, trong nghiên cứu này là $4 \%$. Vậy $n \geq 92$. Trong nghiên cứu này $\mathrm{n}=155$.

- Xử lý số liệu: bằng phần mềm SPSS 22.0; $\mathrm{p}<0,05$ được coi là có ý nghĩa.

\section{KẾT QUẢ}

Nghiên cứu hồ sơ của 155 bệnh nhân được

\subsection{Kết quả phẫu thuật}

Bảng 3.1: Một số đặc điểm kỹ thuật trong mổ

\begin{tabular}{|l|l|c|}
\hline Kỹ thuật & Số BN & Tỷ lệ \% \\
\hline Miếng vá xuyên vòng van ĐMP & 60 & 38,70 \\
Tạo van ĐMP một lá (monocusp) & 27 & 17,42 \\
Mở rộng nhánh ĐMP & 6 & 3,87 \\
Sửa van ba lá & 59 & 38,06 \\
Thay hoặc sửa van ĐMC & 4 & 2,58 \\
Sửa van hai lá & 1 & 0,64 \\
Đóng lỗ bầu dục & 30 & 19,35 \\
Đóng lỗ thông liên nhĩ & 8 & 5,16 \\
\hline
\end{tabular}

- Thời gian cặp ĐMC: 76,55 × 27,91 phút, (31 - 191)

- Thời gian THNCT: $112 \pm$ 38,03 phút, $(52$ - 224)

- Chênh áp tối đa TP- ĐMP (mmHg): 18,87 × 11,60 (2- 54)

- Tỷ lệ áp lực tối đa TP/TT: 0,57 $\pm 0,16(0,25-0,98)$

\subsection{Kết quả sớm sau phẫu thuật}

- Thời gian thở máy trung bình: 20,00 \pm 30,04 giờ (2 -144)

\section{1.Đặc điểm trước phẫu thuật}

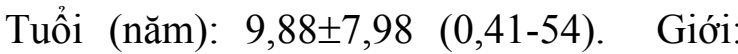

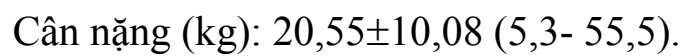

NYHA I:0\%, II:76,13\%, III: 23,23\%, IV:

Ngất: 16,1\%. Ngồi xổm gắng sức 45,2\%. Tím 97,4\%. Ngón tay dùi trống 70,15\%. Cầu Blalock 15,5\%. Biến chứng não 5,8\%. Suy tim nặng (EF 30\%) 1,29\%. 
Bảng 3.2: Biến chứng sau phẫu thuật

\begin{tabular}{|l|c|c|}
\hline Biến chứng & Số bệnh nhân & Tỷ lệ\% \\
\hline Hội chứng cung lượng tim thấp & 13 & 8,38 \\
Chảy máu hậu phẫu & 10 & 6,45 \\
Suy hô hấp cần đặt lại NKQ & 7 & 4,51 \\
Tràn dịch màng phồi & 5 & 3,22 \\
Nhiễm trùng huyết & 1 & 0,64 \\
Tràn dịch màng tim & 1 & 0,64 \\
Viêm nội tâm mạc & 1 & 0,64 \\
\hline
\end{tabular}

Tổng số 43 biến chứng xảy ra ở 32 bệnh nhân. Tỷ lệ biến chứng là 20,64\%.

- Phẫu thuật lại sớm: 4 bệnh nhân (2,56\%) gồm: 1 cầm máu xương ức, 1 khâu liệt cơ hoành, 1 dẫn lưu tràn dịch màng tim, 1 vá lại TLT do Osler .

- Tử vong sớm sau phẫu thuật: 2 trường hợp (1,29\%): 1 do sặc sữa sau khi đã rút nội khí quản ở trẻ 1 tuổi ; 1 do chảy máu phế quản nặng ở bệnh nhân 21 tuổi.

- Thời gian nằm viện hậu phẫu: Trung bình 11,72 \pm 7,21 ngày (2- 56 ngày)

- Kết quả siêu âm tim:

+ Hở van ba lá, mức $<1 / 4=70,59 \% .2 / 4=23,53 \% .3 / 4=5,88 \% .4 / 4=0 \%$.

+ Hở van ĐMP mức <1/4= 57,52\%. 2/4=33,98\%. 3/4 = 8,5\%. 4/4=0\%.

+ TLT tồn lưu: 17/153 (11,11\%). Tất cả TLT tồn lưu kích thước < 3 mm

+ Chênh áp TP-ĐMP (mm Hg): 25,24 = 12,02 (4,7- 58)

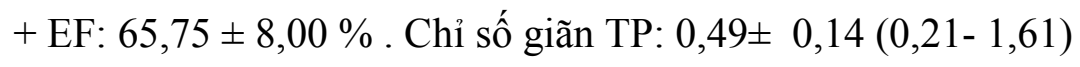

- Điện tim: block nhĩ thất 0\%.Thời gian QRS: 0,06 $\pm 0,028$ giây.

\subsection{Kết quả sau phẫu thuật 6 tháng}

-Triệu chứng cơ năng: NYHA I: 98\%. NYHA: II 2\%. NYHA III,IV 0\%.

-Điện tim: Bloc nhĩ thất: 0\%. Loạn nhịp: 0\%. Thời gian QRS: 0,07 $\pm 0,027$ (giây).

-Phẫu thuật lại: $0 \%$. Tử vong ngoại viện: $0 \%$.

Bảng 3.3. Sự thay đổi một số thông số trước và sau mổ 6 tháng

\begin{tabular}{|l|l|l|l|l|}
\hline \multicolumn{2}{|l|}{ Thông số } & Trước mổ & Sau 6 tháng & p \\
\hline NYHA (trung bình) & $2,24 \pm 0,44$ & $1,01 \pm 0,14$ & $\mathbf{0 , 0 0 0}$ \\
\hline \multirow{2}{*}{ Siêu âm tim } & Chênh áp TP-ĐMP (mmHg) & $80,76 \pm 18,11$ & $21,93 \pm 13,05$ & $\mathbf{0 , 0 0 0}$ \\
& EF (\%) & $64,94 \pm 8,89$ & $64,69 \pm 7,74$ & 0,690 \\
& Chỉ số giãn TP & $0,61 \pm 0,25$ & $0,42 \pm 0,10$ & $\mathbf{0 , 0 0 0}$ \\
& & & \\
\hline
\end{tabular}


Bảng 3.4: Sự thay đổi một số thông số khi ra viện và sau 6 tháng

\begin{tabular}{|l|l|c|c|c|}
\hline \multicolumn{2}{|c|}{ Thông số } & Ra viện & Sau 6 tháng & p \\
\hline Điện tim & QRS (giây) & $0,06 \pm 0,028$ & $0,07 \pm 0,027$ & 0,056 \\
\hline Siêu âm tim & Độ hở ba lá & $1,35 \pm 0,59$ & $1,32 \pm 0,58$ & 0,672 \\
& Độ hở van ĐMP & $1,51 \pm 0,65$ & $1,60 \pm 0,74$ & 0,238 \\
\hline
\end{tabular}

\subsection{Kết quả xa sau phẫu thuật}

60 bệnh nhân đạt thời gian theo dõi sau mổ từ 3 năm trở lên.

Bảng 3.5: Sự thay đổi các thông số sau phẫu thuật 6 tháng và trên 3 năm

\begin{tabular}{|l|l|l|l|}
\hline \multicolumn{1}{|c|}{ Thông số } & Sau 6 tháng & Sau $\geq \mathbf{3}$ năm & p \\
\hline NYHA trung bình & $1,00 \pm 0,00$ & $1,00 \pm 0,17$ & 0,998 \\
\hline QRS (giây) & $0,07 \pm 0,028$ & $0,07 \pm 0,031$ & 0,894 \\
\hline Độ hở ba lá & $1,34 \pm 0,60$ & $1,35 \pm 0,59$ & 0,877 \\
Độ hở van ĐMP & $1,62 \pm 0,74$ & $1,65 \pm 0,79$ & 0,521 \\
Chênh áp tối đa TP-ĐMP (mm Hg) & $22,53 \pm 13,36$ & $20,26 \pm 12,81$ & 0,866 \\
Chỉ số giãn TP & $0,42 \pm 0,10$ & $0,43 \pm 0,08$ & 0,078 \\
\hline
\end{tabular}

- Phẫu thuật lại: 1/153 (0,65\%) do hẹp phễu TP tái phát

- Tử vong xa sau phẫu thuật: $0 \%$.

\section{BÀN LUẬN}

\section{1. Đặc điểm bệnh nhân}

Điểm nổi bật của các bệnh nhân trong mẫu nghiên cứu là tỷ lệ nam nhiều hơn nữ $(61,3 \%$ so với 38,7\%); đa số bệnh nhân đến viện muộn với tuổi phẫu thuật trung bình là 9,88 tuổi $(0,41-54$ tuổi). Triệu chứng nổi bật ở các bệnh nhân TOF là triệu chứng của bệnh tim bẩm sinh có tím: tím $97,4 \%$ với các mức độ khác nhau; ngón tay dùi trống 70,15\%, cơn tím ngất 16,1\%, ngồi xổm khi gắng sức $45,20 \%$, NYHA II chiếm tỷ lệ cao nhất $(76,13 \%)$. Nghe tim có tiếng thổi tâm thu ổ van ĐMP 85,8\%. Đặc biệt ở những bệnh nhân TOF già có biến chứng não- màng não $5,8 \%$, suy tim nặng (EF 30\%) 1,29\%.

\section{phẫu thuật \\ 4.2 Những kết quả trong quá trình Đặc điểm kỹ thuật \\ - Kỹ thuật cắt khoét hẹp đường ra thất phải:} 155 bệnh nhân TOF trong nghiên cứu này đều được phẫu thuật theo phương pháp không mở TP. Theo mô tả lần đầu của Hudspeth $\mathrm{AS}$ : cắt lá trước-vách van ba lá khỏi vòng van, qua đó cắt bỏ cơ phì đại đường ra TP và vá TLT [2]. Ngày nay, kĩ thuật đã thay đổi: dùng dụng cụ vén lá van lên, kết hợp hai đường: qua van ĐMP và van ba lá để cắt bỏ cơ phì đại phễu TP. Việc kết hợp này cho phép nhìn rõ tổn thương hơn, vì thế giải phóng hẹp đường ra $\mathrm{TP}$ hiệu quả và tránh làm tổn thương một số cấu trúc quan trọng (van ĐMP, van ĐMC, ТР...).

- Miếng vá xuyên vòng van ĐMP: Tỷ lệ của chúng tôi là $38,7 \%$. Chỉ định mở rộng vòng van ĐMP bằng miếng vá khi giá trị $Z$ vòng van $<-2$ hoặc khi tim đập lại mà chênh áp tối đa TP-ĐMP > 50 mm Hg (Karl TR [3]). Sau khi mở rộng vòng van bằng miếng vá, giá trị $\mathrm{Z}$ của vòng van (mới) phải đạt từ 0 đến +2 . Riêng ở trẻ nhỏ có $\mathrm{BSA}<0,5$ $\mathrm{m}^{2}$, để tránh hẹp tồn lưu, chúng tôi đã mở rộng vòng van ĐMP khi giá trị $Z$ vòng van $<0$. 
Chúng tôi làm một cách hệ thống van ĐMP một cánh (monocusp) cho những trường hợp phải mở $>5 \mathrm{~mm}$ qua vòng van về phía phễu TP hoặc cắt hết lá van ĐMP xơ dày mất chức năng (17,42\% bệnh nhân- bảng 2).

- Can thiệp trên các van tim: Một số trường hợp van ba lá hở do giãn mép trước vách sau mổ. Cần chủ động khâu vài mũi để khép mép trước vách. Tỷ lệ khâu trong nghiên cứu này là $38,6 \%$ (bảng 2). Gần đây, chúng tôi khâu mép trước vách cho tất cả các trường hợp.

4 trường hợp hở van $\mathrm{ĐMC}$, trong đó 1 bệnh nhân 6 tuổi hở 2,5/4 sửa van cho kết quả tốt. Ba trường hợp còn lại hở 4/4 trên bệnh nhân "Fallot già", bắt buộc phải thay van ĐMC. Cần thay van cỡ vừa phải tránh hẹp đường ra $\mathrm{TP}$.

Áp lực các buồng tim ngay sau ngùng tuần hoàn ngoài cơ thể

Chênh áp tối đa TP-ĐMP trung bình là $18,87 \pm 11,60 \mathrm{~mm} \mathrm{Hg}(2-54 \mathrm{~mm} \mathrm{Hg})$, tỷ lệ áp lực tối đa TP/TT trung bình là $0,57 \pm 0,16(0,25$ $0,98)$. Với phương pháp không mở TP, tỷ lệ áp lực tối đa $\mathrm{TP} / \mathrm{TT} \leq 1$ và chênh áp tối đa TP-ĐMP $\leq 50 \mathrm{~mm} \mathrm{Hg}$ là chấp nhận được, diễn biến sau mổ rất thuận lợi.

\subsection{Kết quả sớm sau phẫu thuật}

\section{Thời gian thở máy}

Thời gian thở máy trong nghiên cứu này là $20,00 \pm 30,04$ giờ (2-144 giờ)ngắn hơn so với các nghiên cứu được phẫu thuật theo phương pháp có mở TP như của Lê Quang Thứu 44,79h [4], của Dyamenahalli U (74 h)[5].

\section{Biến chứng sau phẫu thuật}

32 bệnh nhân có biến chứng, chiếm tỷ lệ $20,64 \%$. Suy tim và hội chứng cung lượng tim thấp có tỷ lệ cao nhất: $8,38 \%$, trong đó có 2 bệnh nhân $(1,3 \%)$ suy thận cấp cần lọc màng bụng. Trong nghiên cứu của Lê Quang Thứu, hội chứng cung lượng tim thấp chiếm tỷ lệ $6,56 \%$, tất cả đều kèm suy thận cấp cần lọc màng bụng [4]. Tỷ lệ cần lọc màng bụng sau phẫu thuật sửa triệt để
TOF theo Dyamenahalli U là 6,74\% [5].

Biến chứng chảy máu hậu phẫu gặp ở 10 bệnh nhân (6,45\%). 9/10 trường hợp đã được điều trị nội khoa ổn định.

7 trường hợp có biến chứng suy hô hấp cấp bao gồm: viêm phổi 3 , xẹp phổi 3 , liệt cơ hoành 1. Tất cả 7 trường hợp này đều cần đặt lại nội khí quản. Biến chứng này thường xảy ra ở trẻ nhỏ, nó làm tăng đáng kể thời gian thở máy trung bình của cả mẫu nghiên cứu.

Tràn dịch màng phổi ở 3,22\% trường hợp. Tỷ lệ này theo nghiên cứu của Dyamenahalli $U$ là $41,57 \%$ [5]. Tràn dịch màng tim gây ép tim gặp ở 1 bệnh nhân $(0,64 \%)$. Để hạn chế và giảm nhẹ hậu quả nếu biến chứng xảy ra, chúng tôi chủ động mở và dẫn lưu màng phổi hai bên cho bệnh nhân có $\mathrm{BSA}<0,5 \mathrm{~m}^{2}$, lưu 48 giờ hoặc dài hơn nếu có hiện tượng tăng tiết dịch.

Block nhĩ thất không gặp ở bệnh nhân nào, so với tỷ lệ $0,6-5 \%$ theo Kirklin và một số tác giả khác [1], [5]

Trong nghiên cứu này, tỷ lệ nhiễm trùng huyết là $0,64 \%$, viêm nội tâm mạc là $0,64 \%$. Tỷ lệ này thấp hơn của Dyamenahalli $U$ : nhiễm trùng huyết $4,5 \%$, viêm nội tâm mạch $1,1 \%$, viêm trung thất $3,4 \%$ [5].

Tỷ lệ phẫu thuật lại sớm là 2,56\%, gồm một mổ lại cầm máu, một khâu căng cơ hoành do liệt, một dẫn lưu màng ngoài tim, một vá lại lỗ TLT do viêm nội tâm mạc làm bung miếng vá. Tất cả có diễn biến tốt sau mổ, không di chứng.

\section{Tử vong sớm sau phẫu thuật}

2 bệnh nhân tử vong chiếm 1,29\%. Một do sặc sữa sau khi đã rút NKQ một ngày, một sau mổ 4 ngày có chảy máu phế quản nặng dẫn đến tử vong.

Tỷ lệ này tương đương với tỷ lệ được thông báo bởi các tác giả tiến hành cùng phương pháp: Karl TR (1,3\%) [3], và thấp hơn nhóm theo phương pháp có mở TP: 7,3\% theo Lê Quang Thứu [4], 7\% theo Dyamenahalli U [5]. 
Vì chỉ có 2 bệnh nhân tử vong nên chúng tôi không thể tìm được các yếu tố nguy cơ. Cả hai trường hợp tử vong này không liên quan đến kỹ thuật mổ.

\subsection{Kết quả khi ra viện và 6 tháng sau phẫu thuật}

Tất cả bệnh nhân được theo dõi ít nhất 6 tháng sau mổ. Kết quả trung hạn được phân tích trên 153 bệnh nhân, đạt 100\% trường hợp sống sau mổ.

\section{Triệu chứng cơ năng}

NYHA trung bình sau mổ của bệnh nhân cải thiện rõ rệt so với trước mổ $(1,01 \pm 0,14$ so với $2,24 \pm 0,44)$. Sự giảm này có ý nghĩa thống kê với $\mathrm{p}=0,000$. Sự cải thiện triệu chứng cơ năng chủ yếu do không còn tình trạng thiếu oxy mô.

Theo Kirklin, những yếu tố làm giảm khả năng hoạt động thể lực sau mổ được xác định là: tuổi phẫu thuật đã lớn ( $>12$ tuổi), chênh áp TPĐMP > 50 mm Hg hoặc tỷ lệ áp lực TP/TT > 0,7, hở van ĐMP do có miếng vá xuyên vòng van, còn TLT tồn lưu lớn [1].

\section{Điện tâm đồ}

Tỷ lệ block nhĩ thất là $0 \%$, tỷ lệ loạn nhịp là $0 \%$. Thời gian QRS sau 6 tháng tăng lên so với khi ra viện $(0,07 \pm 0,027$ giây so với $0,06 \pm 0,028$ giây) nhưng sự tăng này không có ý nghĩa thống kê (bảng 4). Theo Nakazawa M, QRS > 0,120 giây liên quan với tăng nguy cơ loạn nhịp thất, QRS $\geq 0,180$ giây là yếu tố dự báo của loạn nhịp thất, đột tử [6].

\section{Siêu âm tim}

- Hở van ba lá: Không có sự khác biệt giữa khi ra viện và sau 6 tháng .

- Hở van ĐMP: Độ hở van ĐMP trung bình sau 6 tháng có lớn hơn khi ra viện (khi ra viện: 1,51 $\pm 0,65$; sau 6 tháng: 1,60 $\pm 0,74)$ nhưng sự tăng này không có ý nghĩa thống kê (bảng 4). Hở van ĐMP tăng lên là do một số trường hợp van ĐMP một cánh nhân tạo đã mất dần chức năng. Karl TR cho rằng, sau 7,5 tháng các van một cánh sẽ mất dần tác dụng [3].

- Chức năng thất trái: EF trung bình: $64,69 \pm 7,74 \%$, so với trước phẫu thuật, sự thay đổi không có ý nghĩa thống kê $(p=0,69)$.

Phẫu thuật lại và tử vong muộn sau phẫu thuật

Tỷ lệ phẫu thuật lại và tử vong muộn trong nghiên cứu của chúng tôi là $0 \%$ sau 6 tháng theo dõi.

\subsection{Kết quả lâu dài}

Có tất cả 60 bệnh nhân đạt thời gian theo dõi từ 3 năm trở lên.

Lâm sàng: các bệnh nhân đều có hoạt động cơ năng bình thường, so với thời điểm 6 tháng sau mổ, không có sự khác biệt về phân độ NYHA (Bảng 5).

Điện tâm đồ: Thời gian QRS không thay đổi so với thời điểm 6 tháng (Bảng 5).

Độ hở van ba lá, van ĐMP, chỉ số giãn TP:

Theo bảng 5, độ hở trung bình van ba lá, van ĐMP, chỉ số giãn TP tăng nhẹ ở thời điểm theo dõi sau 3 năm so với 6 tháng, tuy nhiên sự khác biệt không có ý nghĩa thống kê $(p>0,05)$. Như vậy, kết quả phẫu thuật của bệnh nhân là ổn định qua thời gian theo dõi trên 3 năm. Các bệnh nhân được phẫu thuật theo phương pháp mở TP trong nghiên cứu của Udekem cho kết quả ngược lại: mức độ giãn $\mathrm{TP}$ và hở van ĐMP tăng dần từ thời điểm trên 3 năm $(\mathrm{p}<0,05)$ [7]. Udekem đưa ra kết luận: nhóm có miếng vá xuyên vòng van và nhóm có miếng vá khu trú vùng phễu đều làm tăng tỷ lệ hở van ĐMP nặng và tăng chỉ số giãn TP một cách có ý nghĩa so với nhóm được mở TP nhưng khâu trực tiếp sau đó [7] Việc cắt thành trước phễu TP làm phễu TP mất khả năng co bóp, kết hợp với miếng vá di động nghịch thường làm suy TP ngay sau mổ và cả khi theo dõi xa. Phương pháp không mở TP làm giảm tổn thương cơ $\mathrm{TP}$, giảm tỷ lệ (và diện tích) miếng vá đường ra $\mathrm{TP}$ nên bảo tồn chức năng $\mathrm{TP}$. Đó là bằng chứng thuyết phục khẳng định ưu điểm của phương pháp không mở TP. 


\section{Phẫu thuật lại}

Tỷ lệ mổ lại là $0,65 \%(1 / 153)$ do hẹp phễu TP tái phát. Sau mổ bệnh nhân ổn định. Tỷ lệ mổ lại theo lê Quang Thứu là 1,58\% [4]. Chỉ định mổ lại khi có hẹp tồn lưu hoặc hẹp tái phát đường ra TP với mức chênh áp tối đa TP-ĐMP $>50 \mathrm{~mm}$ Hg hoặc áp lực buồng TP $>60 \mathrm{mmHg}$ [1]. Với TLT tồn lưu, mổ lại khi đường kính lỗ $>5 \mathrm{~mm}$ và lưu lượng tuần hoàn phổi/tuần hoàn hệ thống > 1,5 [1]. Thay van ĐMP khi có hở van nặng, hạn chế hoạt động thể lực, loạn nhịp tim, siêu âm thấy buồng TP giãn tiến triển (chỉ số giãn TP> 1), giảm chức năng TP $(<40 \%)[3]$.

\section{Tử vong muộn sau phẫu thuật}

Cho tới thời điểm hiện tại, chúng tôi không thấy có trường hợp nào tử vong ngoại viện. Hầu hết các ý kiến đều cho rằng, tỷ lệ tử vong muộn sau phẫu thuật triệt để TOF là rất thấp, khoảng $2 \%$ sau 20 năm. Tỷ lệ này tương đương ở người bình thường. Các nguyên nhân gây tử vong chủ yếu là suy tim, giãn $\mathrm{TP}$ và loạn nhịp thất gây đột tử [1], [3].

\section{IV.KẾT LUẬN}

Qua nghiên cứu 155 bệnh nhân TOF được phẫu thuật triệt để tại bệnh viện Tim Hà Nội giai đoạn 1/2011-1/2015 chúng tôi kết luận: kết quả rất khả quan với tỷ lệ biến chứng và tử vong sau mổ thấp $(1,29 \%)$. Bệnh nhân ổn định qua thời gian theo dõi dài: triệu chứng cơ năng cải thiện, cấu trúc tim ổn định: độ hở van tim, chỉ số giãn thất phải, chênh áp TP- ĐMP không tăng, tỷ lệ mổ lại thấp $(0,65 \%)$. Phương pháp không mở thất phải chính là một cuộc cách mạng trong phẫu thuật sửa triệt để TOF.

\section{TÀI LIỆU THAM KHẢO}

\section{Kirklin JW; Boyes B; Kouchoukos} NT, (2003), Ventricular Septal Defect and Pulmonary Stenosis or Atresia, in Cardiac Surgery,1, Churchill Livingstone, Philadelphia, pp. 946- 1074.

\section{Hudspeth AS, Cordell AR, Johnson} FR, (1963), "Transatrial Approach to Total Correction of Tetralogy of Fallot", Circulation (27), pp.796-800.

3. Karl TR (2008), Tetralogy of Fallot: Current surgical perspective, Annals of Pediatric Cardiology, 1 (2) , pp. 93-100

4. Lê Quang Thứu (2008), Nghiên cứu điều trị phẫu thuật sửa chữa toàn phần bệnh Tứ chứng Fallot, Luận án tiến sĩ y học, Học viện Quân y.

\section{Dyamenahalli U, Mc Crindle BW et al,} (2000), "Infuence of Perioperative Factors on Outcomes in Children Younger Than 18 Months After Repair of Tetralogy of Fallot", Ann Thorac Surg, (69), pp.1236-42.

6. Nakazawa M, Shinohara T, Sasaki A, et al, (2004), "Arrhythmias late after repair of tetralogy of Fallot- a japanese multicenter study", Circulation (68), pp.126 - 130

7. Udekem Y, Ovaert C, Grandjean F, Gerin V,. Cailteux M, Shango-Lody P, Vliers A, Sluysmans T, Robert A, Rubay J (2000), “ Tetralogy of Fallot, Transannular and Right Ventricular Patching Equally Affect Late Functional Status", Circulation. (102), p.111-116. 